\title{
Grasp Actually: An Evolutionist Argument for Enactivist Mathematics Education
}

\author{
Dor Abrahamson \\ Graduate School of Education, University of California Berkeley, Berkeley, CA, USA
}

\author{
Keywords \\ Constructivism · Design · Education · Enactivism • \\ Mathematics
}

\begin{abstract}
What evolutionary account explains our capacity to reason mathematically? Identifying the biological provenance of mathematical thinking would bear on education, because we could then design learning environments that simulate ecologically authentic conditions for leveraging this universal phylogenetic inclination. The ancient mechanism coopted for mathematical activity, I propose, is our fundamental organismic capacity to improve our sensorimotor engagement with the environment by detecting, generating, and maintaining goal-oriented perceptual structures regulating action, whether actual or imaginary. As such, the phenomenology of grasping a mathematical notion is literally that - gripping the environment in a new way that promotes interaction. To argue for the plausibility of my thesis, I first survey embodiment literature to implicate cognition as constituted in perceptuomotor engagement. Then, I summarize findings from a design-based research project investigating relations between learning to move in new ways and learn-
\end{abstract}

ing to reason mathematically about these conceptual choreographies. As such, the project proposes educational implications of enactivist evolutionary biology.

(c) 2021 S. Karger AG, Basel

My interest in immediate coping does not mean that I deny the importance of deliberation and analysis. My point is that it is important to understand the role and relevance of both cognitive modes.

(Varela, 1999, p. 18)

\section{Preamble: Attentional Anchors Grounding Mathematical Notions}

The reader is kindly invited to partake in a brief activity that should help us immediately establish some essential common ground with regards to a key hypothetical construct, an attentional anchor, that will be thematic to the argument put forth in this paper. Please imagine a large L-shape inscribed on your desk. You may wish to mark this L-shape on paper, but you need not. The Lshape is composed of a vertical line and a horizontal line. Viewed as a $y$-axis and $x$-axis, respectively, this L suggests 
the first quadrant of the Cartesian plane. Your task is as follows. Place the index fingertips of both your left hand $(\mathrm{LH})$ and right hand ( $\mathrm{RH})$ at the origin (the L's corner). Now, move your LH up/down along the $y$-axis, even as you move your RH right/left along the $x$-axis, with the additional caveat that RH's distance from the origin is always double LH's distance from the origin. In a sense, you are asked to move RH twice as fast as $\mathrm{LH}$, thus coordinating your hands' motor action simultaneously, orthogonally, proportionately.

Most people find it quite challenging to enact this bimanual movement. Yet, as we have learned from the mouths of our 10-year-old study participants, performing this task can be dramatically facilitated if you now introduce an auxiliary construction into the activity space. Begin by positioning $\mathrm{LH}$ and $\mathrm{RH}$ at any pair of $1: 2$ distances from the origin. Now, imagine a diagonal line connecting LH and RH. Notice this diagonal's acute angle with the $x$-axis. Then, move this imaginary LH-RH diagonal connector to the right, all the while keeping its angle to the horizontal axis constant. It is as though you are dilating a right triangle composed of two legs extending along the axes and an elongating diagonal as the hypotenuse. When we track the eye gaze of people engaged in this activity, we note that their attention deflects away from their hands and onto the diagonal, as though it is a new thing that they are handling. This new phenomenal object has inherent properties, such as its length, and it has relational properties, such as its angle with the $x$-axis. As you displace this object along a horizontal trajectory, you keep its relational property of angularity invariant. You are thus self-imposing a constraint on how you may move this object. Moreover, you can describe this imaginary object, get another person to perceive it (as I have got you to perceive it), see it as part of a larger mathematical composition (the right triangle), and even copy it with a pencil onto paper, measure it, and so on.

How should we think of what you have just experienced and accomplished? Specifically, as you reflect on your engagement in this task, what is your phenomenology of your own cognitive activity? You were presented with a motor-control task. As you attempted to perform this task, you may have realized that it was taxing your cognitive capacity to coordinate two independent motor actions, to the point where it felt that meeting the task requirements might require a different approach. I then offered you instructions for modifying how you were attending to the situation. This new attentional orientation toward your immediate environment gave you a new grip on the world: Perhaps perceiving the diagonal line let you enact the LH-RH 1:2 movement more effectively and smoothly.

Hutto and Sánchez-García (2015) call these perceptual orientations, which facilitate the enactment of movement, attentional anchors - these orientations selectively foreground elements, regions, or other aspects of the environment to tighten our purposive interactions with the world. Attentional anchors may be discovered, as in the case of our study participants (Abrahamson \& Trninic, 2015), cued (Liao \& Masters, 2001; Newell \& Ranganathan, 2010), as in our orthogonal-lines activity just now, or co-constructed (Shvarts \& Abrahamson, 2019), as in tutorial sessions. Abrahamson and Sánchez-García (2016) claim that attentional anchors, while instrumental in solving motor-control impasses and thus enabling new feats in the physical practices, can also be experienced as new ontologies that reveal mathematical patterns, similar to the dilating right-triangles in our task. Duijzer et al. (2017) used eye-tracking instruments to document the variety of attentional anchors that mathematics students discover spontaneously as their means of solving bimanual motor-control tasks. Bongers et al. (2018) have documented students creating paper-and-pencil representations of their attentional anchors, such as drawing the imaginary diagonal line, measuring it, and elaborating on this construction through arithmetic procedures. Similar results have been demonstrated with regards to other mathematical concepts, such as geometrical area (Shvarts, 2017), trigonometric functions (Alberto et al., 2019), and parabolas (Shvarts \& Abrahamson, 2019).

It thus appears that students can get a first grip on mathematical concepts by spontaneously conjuring new ways of attending to the environment (Hutto et al., 2015). Elsewhere, we have discussed these empirical findings from various theoretical perspectives, including ecological dynamics, enactivism, constructivism, and sociocultural theory, as these bear on mathematics-education research (for a review, see Abrahamson, 2019). In the current conceptual paper, we step back to ask: What are the implications of these findings more broadly, with respect to epistemological theories of mathematical knowledge? At least within the learning environments that we have designed and investigated, it would appear that our natural capacity to improve our grip on the material or virtual environment by changing our perceptual orientation toward it could be implicated as our cognitive means of first grasping mathematical concepts. To the extent that this model is demonstrable more broadly across learning environments and concepts, and to the extent that empirical research continues to substantiate this model, one
78

Human Development 2021;65:77-93 DOI: $10.1159 / 000515680$
Abrahamson 
might then consider that the cultural practice of mathematical reasoning coopts the cognitive capacity for improving our perceptuomotor engagement in the environment. Ancient cognitive wherewithal is thus re-instrumentalized to meet emergent cultural needs. The objective of our paper is to develop this idea of mathematical cognition as utilizing evolutionarily endowed perceptuomotor capacity.

\section{Objective: Motivating an Evolutionary Account of Mathematical Thinking}

What do we do when we do mathematics? The thrust of this paper is to promote the thesis that mathematical thinking, while perhaps a specialized cultural activity, draws on mundane cognitive capacity. Mathematical thinking draws on our biological species' cognitive inclination to adapt our attentional orientation toward the environment to improve the efficacy of our purposive sensorimotor interactions. As such, when we learn new mathematical ideas, we use our primordial knack to get a better grip on stuff we are handling, whether to eat it, control it, ply it, or wield it.

I will argue for this position along conceptual, theoretical, and empirical veins. The conceptual vein looks to the foundations of evolutionary biology to motivate the premise that a species' rarified cognitive skill can evolve as a coopting of existing neural architecture. The theoretical vein will draw on literature from cognitive developmental psychology and enactivist philosophy that supports a view of cognition as constituted in situated, purposeful, multimodal interactions with the environment. The empirical vein will draw on analyses of data from design-based research studies of mathematical teaching and learning that evidence the emergence of attentional patterns regulating the motor enactment of complex bimanual movement - movement that is then pinned down as mathematical structure.

A research problem concerning the origins of mathematical reasoning is worth considering, I maintain, both for its apparent intellectual merit and potential broader impact. Understanding the evolutionary roots of mathematical reasoning would advance the philosophy and theory of cognitive science, because the answers could inform the development of explanatory models accounting for qualities, prerequisites, processes, prospects, and limitations of mathematical reasoning. In turn, if we knew what this evolved capacity is, what it is for, and how it operates "in the wild," perhaps we could better leverage it

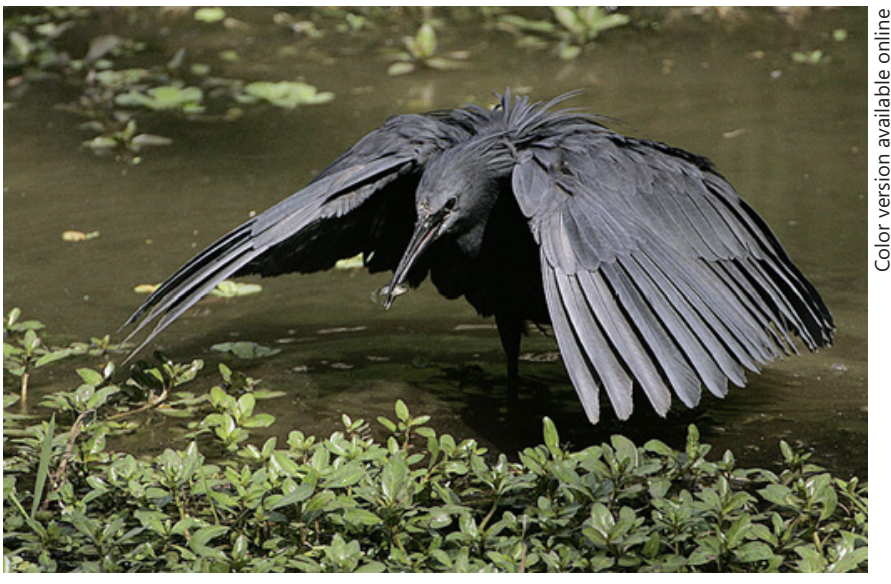

Fig. 1. A black heron canopy-feeding: the bird coopts its flightbound feathers as an embodied parasol casting shadow on water, thus greatly improving its sight of any fish below the surface. $\mathrm{Hu}$ mans perform an analog action when they cup their hand over their eyes to shield the sun.

in the classroom. We could create and facilitate learning environments designed to let students exercise and appreciate this natural capacity, so that they can get and use mathematical ideas and create their own.

\section{Introduction: Conceptual Rationale for an Evolutionary Theory of Mathematical Cognition}

In his paradigm-changing On the Origin of Species by Means of Natural Selection, Charles Darwin (1859) posits the following to account for observed morphological variability in organic forms of an avian species distributed geographically over multiple habitats across an archipelago.

[T] hese [material organic] parts [are] perhaps very simple in form; ... then natural selection, acting on some originally created form, will account for the infinite diversity in structure and function [of the forms] ... Any change in function, which can be effected by insensibly small steps, is within the power of natural selection. (pp. 435-456)

More than a century later, Stephen Jay Gould and Elisabeth Vrba published in Paleobiology an article that put forth the neologism exaptations - species' biological "characters, evolved for other usages (or for no function at all), and later 'coopted' for their current role" (Gould \& Vrba, 1982, p. 6). Unlike the more familiar adaptations, where "natural selection shapes the character for a current use" (p. 5), exaptations coopt biological characters in one 
of two manners: (a) "A character, previously shaped by natural selection for a particular function (an adaptation), is coopted for a new use"; or (b) "A character whose origin cannot be ascribed to the direct action of natural selection (a nonaptation) is coopted for a current use" (p. 5) (Fig. 1).

A classic example of Type 1 exaptation is the mutation of feathers: originally selected for their thermoregulatory function, feathers featured only much later through the evolutionary eons in their now-emblematic flight effect (Gould \& Vrba, 1982). In fact, feathers also play myriad non-aeronautic roles that include enhancing hearing, producing sounds, snow-sliding, and canopy-feeding: some birds who prey on fish raise their plumage above their heads as an opaque awning that enshadows the water beneath them, thus facilitating their vision under the surface that otherwise reflects ambient light (Fig. 1). Notably, to configure a canopy serving the fishing function, the heron recruits kinesiological forms originally adapted for enacting the flight function. ${ }^{1}$ As such, in order to understand how a species employs a perceptuomotor capacity to accomplish an exapted function, we examine how it accomplishes the form's original vocational function.

Here, I draw an analogy from canopy-feeding, putting forth that mathematical reasoning, too, exapts an earlier form for a new function. Mathematical reasoning, I propose, exapts our ancient capacity to adapt our perceptual orientation toward the environment, which is what biological organisms constantly do to improve their physical engagement with the environment. This ancient cognitive form was originally selected for, because it functioned to promote organisms' existentially efficacious interactions in the material-biological ecology (Maturana \& Varela, 1987/1992). In turn, this ancient form was exapted in the service of cultural practices that require attending in specialized ways to the environment so as to perceive mathematical structures inherent therein, as we demonstrated in the case of the diagonal attentional anchor. Yet, the thesis holds, this cognitive capacity, being exapted, is still perceptuomotor, just as perceiving the diagonal line served to organize the coordination of bimanual movement. If this thesis is true, then expert mathematical perception, even of static images on blackboards or in textbooks, is cognitively constituted as perceiving-for-acting. And we perceive new mathematical structures, because we are attempting to move in new ways.

1 In analyzing "aptations," Gould and Vrba (1982) associate function with adaptations and effect with exaptations. For simplicity, I will use function more broadly to include effects, thus designating any apparent ecological utility of biological forms, where forms include all genetic organic structures or characters (e.g., material organs, neural architecture).
What might all this mean for mathematics education? In our earlier exercise, we enhanced your motor coordination by highlighting for you a new gestalt, the diagonal line, which we then framed as bearing mathematical meanings. If we are to put this theory to practice, then instructional design should simulate for students ecologically authentic experiences that solicit and accommodate ancient biological forms that evolved to tighten our sensorimotor grip on the world. To bring about conceptual learning, educational activities should present action tasks that are designed such that the targeted perceptual change comes about as a cognitive solution to a motor problem. In turn, introducing educational activities that invite students to introspect into their own perceptuomotor phenomenology is an opportunity for a cultural shift, whereby we lay bare for students the epistemological rationales motivating their mathematics curriculum. That is, philosophical and theoretical ideas underlying an enactivist pedagogical design rationale should be made transparent to students engaging in these activities. In particular, classroom discourse should acknowledge, legitimize, valorize, and leverage our perceptuomotor phenomenology of mathematical reasoning as a collective resource for learning. This conclusion would offer radically different implications for mathematics education than would an epistemological model of mathematical reasoning as the amodal generation and processing of abstract static entities.

I am scarcely the first to query the evolutionary sources of cultural practice (Donald, 1991; Malafouris, 2013). In this tradition, we will trace the footsteps of Casasanto (2010) (see also Jelec, 2014) to consider the evolutionary theory of exaptation as an approach to implicating the ecological roots of mathematics. The evolved biological form of interest in this inquiry is the cognitive capacity for adapting sensory perception to organize hands-on motor action. It is this capacity, I hypothesize, that enables us to learn mathematical ideas.

Below, I will situate this paper within a tradition of form-function scholarship in the research field of cognitive developmental psychology oriented on questions of mathematics education.

\section{Form Changes Function in Mathematical Practice: A View from Sociocultural Theory}

Darwin's seminal evolutionary model pertains to ecological relations between biological forms and their contextual functions. The model thus motivates scholarship
Abrahamson 
Fig. 2. Form-function shifts in Oksapmin's 27-body counting system. a In Oksapmin communities in central Papua New Guinea, the fingers, arms, shoulders, and facial features anchor a sequence of 27 enumerative actions - the completion of the 27 body part enumeration culminates in an exclamation of a fist-raised "fu!" (see https://culturecognition.com/newpage-3). b, c Foreign currency, shillings and pounds ( 20 shillings $=1$ pound) $(\mathbf{b})$, colonized the Oksapmin collective practices of economic exchange; subsequently the "fu" cardinal utterance, traditionally sounded at the completion of the 27 tally process, traveled to the 20th position, marking the enumerative completion of 20 shillings in a pound (c); thus, "fu" shifted in function, now marking the 20th body part and the equivalent of a 1-pound note, and a count of pounds could be expressed as a count of "fu's." d When Papua New Guinea became independent, the country issued a new currency in which a 2-kina note was the equivalent of a pound, and the 2-kina note became a "fu"; subsequently, using the body-part name applied to 2-kina notes equivalent of 6 kina) led to yet a new function for "fu" - a doubling of the value of a body part - thus, shoulder (10th body part) followed by "fu" indicated 20 kina or double the value of the 10th body part, a new doubling function for "fu." (e.g., a count of three 2-kina notes was the
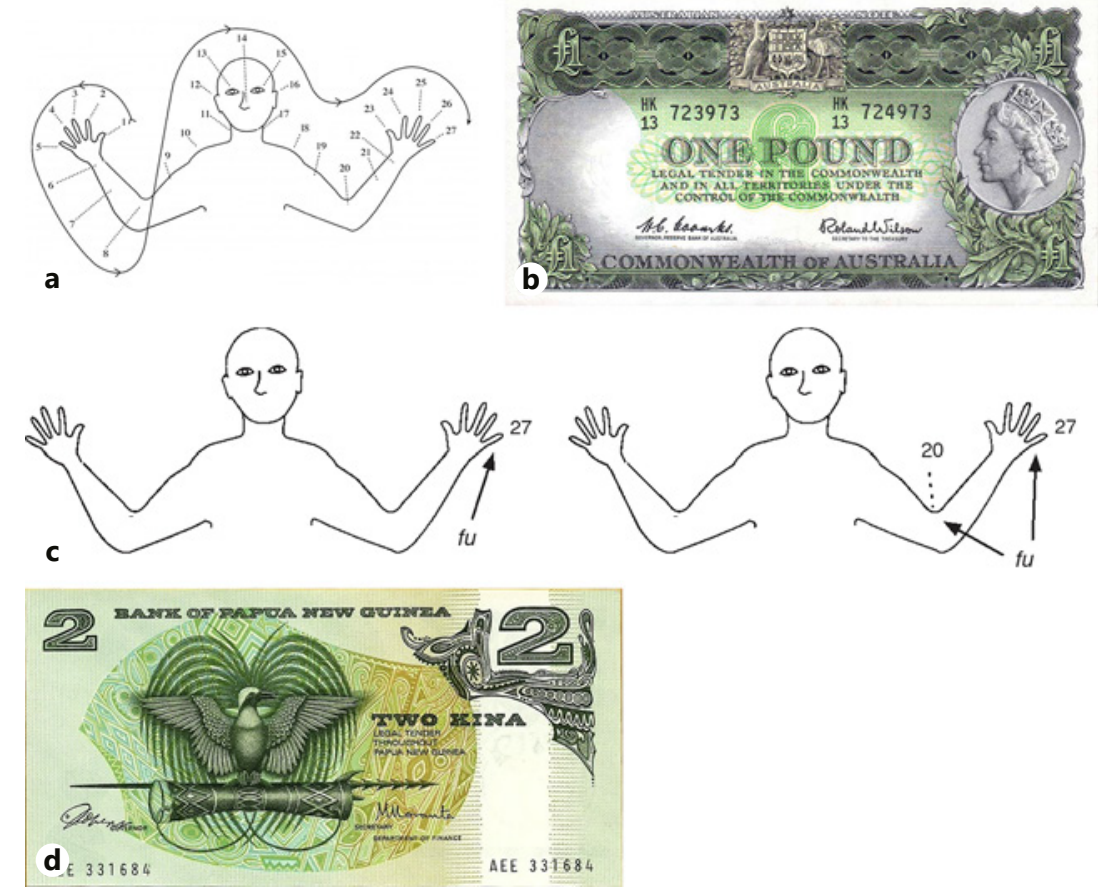

on characters of anatomy, metabolism, and kinesiology as these adapt vis-à-vis ecological constraints on foraging, predation, and procreation. Yet one could plausibly extrapolate the form-function principle of natural selection as it obtains in primordial flora and fauna to Homo sapiens' sociocultural phylogeny, including the functional evolution of practice-based artifacts taken as forms. Indeed, Saxe (2012) developed a theoretical model grounded in form-function dialectics as his analytic means of investigating gradual adaptive changes in a people's cultural practices (Fig. 2).

Saxe is a cognitive developmental anthropologist interested in the origin, transformation, and travel of cultural forms. His studies comprise multi-time-scale laminated analyses of historical evolutions in form-function relations, where a collective of people adapts its social enactment of situated cultural practice amidst shifting ecological contingencies. For example, he demonstrated how the Oksapmin people of Papua New Guinea accommo-

dated their indigenous counting practice, which uses multiple body parts in tallying the cardinality of a set and conducting rudimentary arithmetic, to assimilate features of colonial currency they had to engage (Fig. 2; Saxe, 2012). Notably, the cultural form "fu," whose utterance signifies completion of an embodied tally, relocated from the 27th embodied landmark to the 20th, previously nondescript point, thus assimilating the new currency's calculus (20 shilling $=1$ pound). Later, when the Papua New Guinea currency was introduced, the new 2-kina note replaced the 1-pound note. Consequently, the function of "fu" shifted once more to serve as a multiplicative operator - "fu" now expressed doubling the value of the 10th body tally, the shoulder, which now tallied 1 kina.

A fundamental assumption in evolutionary biology as well as in its applications to anthropology is that the originary function of a form may no longer subsist once the form takes on new functions. As the Oksapmin young are schooled in now-prevalent Hindu-Arabic base-10 math- 
ematics, "fu" might still persevere as a cultural form, perhaps to index a doubling function. This nuanced etymological exaptation may or may not conserve enactive traces of body-based tallying. Presumably, the cultural form "fu" could henceforth function without tacit collective reference to its ancestral enactive sources, so much so that knowing the history of those previous functions may bear little to no pedagogical utility.

In contrast to anthropological examination of cultural forms that emerge and transform in social ecologies, the current article examines our species' embodied cognitive forms that matured eons before cultural practices or material artifacts sprouted in our evolutionary niche (Donald, 1991; Malafouris, 2013). Though tacit and pre-linguistic, ancient enactive forms bear explanatory power in analyzing how we approach contemporary tasks, whether physical (Wilson \& Golonka, 2013), logical (Smith et al., 1999), or symbolic (Landy \& Goldstone, 2007). If we knew what ancient embodied cognitive form engenders mathematical insight and how this form functions, we could imagine a mathematics pedagogy that fosters the active engagement of this form. I submit that ascertaining the embodied cognitive form of mathematical insight is now within our reach. My objective, here, is to frame a research program that develops theories and methodologies to capture the mechanisms of this putative form. I believe this cognitive embodied form is our capacity to modify our perceptual orientation toward the environment to improve our motor engagement.

In the following theoretical section, after a brief framing of the research program, I will attempt to defend my hypothesis by drawing on the following ideas: (a) genetic epistemology (Piaget, 1968), in particular the notion of perceptual routines that emerge through sensorimotor activity as a means of guiding motor action; and (b) the philosophy of enactivist cognition (Varela et al., 1991) that looks to eschew kneejerk allusions both to representations in the head and to objective objects in the environment, instead looking to forge an epistemological theory constituted on intrinsically relational bonds. In a radicalized version of this theory (Hutto \& Myin, 2013, 2017), perceptual attention is proposed as an operational interface between self and environment - attention constitutes a sufficient construct for building explanatory models of the mind.

Building on these resources, I put forth that we improve our operative grip on the concrete environment by adapting our attentional routines toward selected features of the environment. These features may be in flux, either independent of us or as a direct result of our actions on the environment. Though dynamic, these structures bear some invariant collective property respecting stable relations between their elements - our attentional routines enable us to engage these dynamic structures. Such was the case with the diagonal line: as we moved it, we kept it at a constant angle to the horizontal line. It is these dynamically invariant perceptual structures, the attentional anchors, I believe, that we think about, with, and through when we think mathematically.

Stepping back, this article draws on the construct of exaptation to promote a theoretical implication of primordial biological forms as critical to the task of modeling modern cognitive functions. This argumentative grammar is grounded in epistemological philosophy, which I now outline.

\section{Theoretical Antecedents to a View of Knowing as Gripping}

How should we think about learning? This section situates this paper's pursuit of an evolutionary account for mathematical reasoning within a larger research program to promote mathematics education through understanding the nature and potential of cognitive development in the sociocultural context. A theoretical commitment to attentional anchors as critical cognitive vehicles of mathematical reasoning motivates efforts both to inquire into literatures supporting this view and, through this inquiry, to take practical measures toward occasioning opportunities for students to develop attentional anchors relevant to the mathematical concepts they are to learn.

The logical premise of any theory of mathematics learning is to identify and model biological and ecological structures and mechanisms accounting for observed developmental changes in individuals' manifest skill. Yet, what ontologies of structure and mechanism should we examine? What events account for developmental change? What should be the unit of analysis in investigating these events as developmental processes (Araújo et al., 2020; Damşa \& Jornet, 2020) - should we look at a student alone or a student in interaction with a teacher and peers? Thus, who are the participants in these events, what resources do they draw on, and how is development accomplished? To build an evolutionary account of mathematical reasoning, we must first identify an epistemological model that will serve as our theoretical substrate.

This article subscribes to the dialectical approach to theorizing teaching and learning (diSessa et al., 2015) - an approach that looks to combine the legacies of both Piaget and Vygotsky in theorizing individuals' construction
Abrahamson 
of cognitive structure as a sociocultural achievement. I propose to call this theoretical approach enculturated epigenesis, so as to capture and foreground a commitment to the complementary lenses of both Piagetian and Vygotskian theory. Theories of enculturated epigenesis go beyond simplistic Piaget-versus-Vygotsky antinomy (Cole \& Wertsch, 1996) to model how participating in the guided social enactment of cultural practice occasions for learners opportunities both to recruit their early developed knowhow and to attribute disciplinary meaning to any new structures emerging from these experiences (Abrahamson, 2009; Flood, 2018; Shvarts \& Abrahamson, 2019).

This article also subscribes to transformative approaches to theorizing teaching and learning. Stetsenko (2017) argues for a historically authentic revisionist reading of Vygotsky as rallying societies to promote their own ongoing reconfiguration by means of educating their young for revolutionist agency. I propose a view of design-based research as a transformative paradigm that aspires to mobilize positive cultural change by both implicating and tackling problems of pedagogy (Cobb et al., 2003). As such, when they engineer experimental responses to problems of pedagogy, design-based educational researchers ask not what personal resources participants draw on per se when participating in the social enactment of curriculum as currently practiced but - transformatively - what resources they should draw on in a revised curriculum. A transformative orientation to educational practice invites both critical evaluation of mainstream curriculum and the innovation of design solutions attentive to students' early ways of knowing (Abrahamson \& Chase, 2020). As such, transformative design straddles the cultural-cognitive saddle of enculturated epigenesis to ask both "What are students to know?" and "What personal resources could we tap so as to foster this knowing?"

Yet what are these alleged personal resources that educational innovators hope to tap? That is, as we design learning environments, including media, tasks, and facilitation protocols, what "principles of biological cognitive systems" (Glenberg, 2006, p. 271) should we cater to? This section overviews two intellectual strains, constructivism and enactivism, to argue that they converge on a similar epistemological account of knowledge as situated coping routines that emerge from purposeful interaction with the environment. This interactionist account of knowledge, I claim, could inform which principles of biological cognitive systems design-based researchers ought to solicit to engage students in learning activities that are to ground mathematical concepts. Specifically, mathematics learning environments should draw on students' innate cognitive capacity to improve their sensorimotor engagement with the environment (Abrahamson \& Trninic, 2015; Nathan \& Walkington, 2017; Ottmar \& Landy, 2017). Reframed from the viewpoint of evolutionary biology, mathematics educators should tap cognitive forms governing our pervasive capacity for perceptuomotor enactment of ecologically coupled movement. It is these ancient organismic forms, I maintain, that humanity exapted to function in beholding, apprehending, and manipulating mathematical objects and, as such, it is these forms that educational practice should draw on for students to ground their mathematics learning.

\section{Genetic Epistemology and Radical Constructivism}

Piaget's grand research program, genetic epistemology, purports to model how genotypical material potentiates phenotypical intelligence. In Genetic Epistemology, Piaget (1968) explains human cognitive ontogenesis as an epigenetic developmental process. Humans begin life without any innate knowledge per se but with an innate capacity to learn through interaction. Namely, learning transpires through and for interacting with the environment. Knowledge, as such, is not a representation of things as they are. Rather, knowledge - or, better, knowing - is inherently an actionable capacity to interact with the environment when the environment appears appropriate for those actions.

Knowing does not really imply making a copy of reality but, rather, reacting to it and transforming it (either apparently or effectively) in such a way as to include it functionally in the transformation systems with which these acts are linked. (Piaget, 1968, p. 6)

When an organism engages the environment as amenable for acting upon in some particular way, the organism is perceiving the environment: the organism is attending to the environment as soliciting particular motor action. Through exploration, pruning, and tuning, this manner of attending stabilizes - it has become formed or constructed as a cognitive structure, and it will more likely guide future encounters of similar purpose and in similar context. Perceptual construction of the sensory manifold is not arbitrary but, rather, intentional, contextual, selective, and synthetic. The act of perceiving is the organism spontaneously devising and organizing a for-action readiness toward the environment. Importantly, perception is not "in the head," just as it is not "in the world." Rather, perception is intrinsically relational, an ad hoc 
subjective sensorimotor configuration that solicits, stages, and guides interaction. Perception is the situated instantiation of knowing (Turner, 1973). In turn, perceptually guided interaction is where learning transpires: interaction shapes and modifies cognitive coordinations between apparent environmental structure and possible motor behavior. Piaget calls this coordination an action schema. This malleable functional form of knowing is the crucible of intelligence.

Importantly, whereas biological capacity to apply action schemata is innate, the action schemata themselves are to develop through the individual's sensorimotor interactions.

[Actions] reproduce themselves exactly if there is the same interest in a similar situation, but they are differentiated or else form a new combination if the need or the situation alters. We shall apply the term "action schemata" to whatever, in an action, can thus be transposed, generalized, or differentiated from one situation to another: in other words, whatever there is in common between various repetitions or superpositions of the same action ... [M] ost schemata, instead of corresponding to a complete inherited apparatus, are built up a bit at a time, and even give rise themselves to differentiations, by adaption to a modified situation or by multiple and varying combinations. (Piaget, 1968, pp. 7-8)

Thus, as an infant begins to grip objects, the multimodal perceptual spectrum of grippable things expands the morphological-kinesiological span of actionable gripping capacity. In Piaget's terms, the sensorimotor gripping schema accommodates through-and-for assimilating the sensory display as prehensible. The gripping form progressively fields objects that vary in color, size, shape, heat, texture, weight, orientation, and so on.

Still, there is an epistemic gap between doing and thinking, or, if you will, there are different ways of knowing: the objects we grip are not initially objects we can reflect on. For the pre-reflective mind, per Piaget, even as we attend to the environment, we do not initially parse it as things - we have not yet objectified the objects we are engaging. Rather, as similarly theorized in various strands of phenomenological philosophy that elaborate on Franz Brentano's notion of intentionality, the acting mind tacitly perceives objects as psychological objectives of motor intentionality (Dreyfus \& Dreyfus, 1999; Merleau-Ponty, 1964), as perceptual-functional types mediating intentionality (Husserl, in Boer, 1978), or as ready-to-hand facets of dasein, namely, immersed intentionality (Heidegger, 1962). Objects of pre-reflective motor intentionality (Sheets-Johnstone, 2015) change their ontic status, when we step back from operating on or through them and, instead, attend to them in a reflective epistemic mode (Koschmann et al., 1998). "[I]t is during breakdowns that the concrete is born" (Varela, 1999, p. 11). Yet one need not wait for breakdown to reflect on what we are manipulating - through appropriate training, mindful attention to the immersing environment can be solicited deliberately (Petitmengin, 2007).

Inspired more so by Piaget's theory of genetic epistemology than by his cognitive developmental psychology studies per se, and building on von Glasersfeld (1987), radical-constructivist scholars of mathematics education have sought to hone core principles of Piaget's theory and apply these principles in modeling the development of mathematical concepts. These clarifications of Piaget's theory insisted that whereas Piaget implicated interaction as the source of intelligence, he denied that what we learn about the world could be viewed as a representation of the world. Explicitly, they argued for an "interactionist but not representationalist view of mathematical knowing and teaching" (Steffe \& Kieren, 1994, p. 728). This view inveighs against "Cartesian anxiety" yet concedes that, nevertheless, these interactionally borne non-representationalist objects of knowing come forth as bona fide mathematical objects through social interaction, namely "languaging" (pp. 723724). Ergo, radical constructivists are sanguine about the prospects of theorizing enculturated epigenesis.

Yet what might a truly radical-constructivist pedagogy look like? How would mathematics educators assemble a learning environment that fosters mathematics knowing founded on engaging motor intentionality prior to languaging these experiences? That is, what curriculum could solicit our species' paleobiological forms that have been exapted for mathematical reasoning? Before addressing this question, we will now briefly discuss another intellectual strand that, though rising from a confluence of cognitive science and Buddhist philosophy, shares with genetic epistemology and phenomenology an implication of cognition as rooted in sensorimotor activity.

\section{Enactivism}

Increasingly, since the closing decades of the 20th century, cognitive science has been undergoing an embodied turn (Nagataki \& Hirose, 2007). This embodied turn, asserts Varela (1999), is exemplified in the enactivist thesis.

[T] here are strong indications that within the loose federation of sciences dealing with knowledge and cognition - the cognitive sciences - the conviction is slowly growing that [...] a radical paradigm shift is imminent. At the very center of this
Abrahamson 
emerging view is the conviction that the proper units of knowledge are primarily concrete, embodied, incorporated, lived; that knowledge is about situatedness; and that the uniqueness of knowledge, its historicity and context, is not a "noise" concealing an abstract configuration in its true essence. The concrete is not a step toward something else: it is both where we are and how we get to where we will be. (p. 7)

He then defines the essence of embodied cognition:

Embodied entails the following: (1) cognition dependent upon the kinds of experience that come from having a body with various sensorimotor capacities; and (2) individual sensorimotor capacities that are themselves embedded in a more encompassing biological and cultural context. (p. 12)

Homing into a distinctive thesis of the enactivist approach, Varela (1999) asserts the following, which speaks to the ecological fit between the organism and the environment it may perceive:

In the enactive approach reality is not a given: it is perceiverdependent, not because the perceiver "constructs" it as he or she pleases, but because what counts as a relevant world is inseparable from the structure of the perceiver. (p. 13)

In particular, Varela explains, "what counts as a relevant world" is contingent on the organism's goal in interacting with the environment, namely what the organism is attempting to actuate.

$[\mathrm{P}]$ erception does not consist in the recovery of a pre-given world, but rather in the perceptual guidance of action in a world that is inseparable from our sensorimotor capacities. (p. 17)

Critically for our discussion of grasping mathematical objects, Varela (1999) believes that “'higher' cognitive structures also emerge from recurrent patterns of perceptually guided action" (p. 17). Not unlike Piaget, Maturana and Varela (1987/1992) sought to build an ambitious theory of human cognition, including "higher" cognition, on an evolutionary implication of organisms' sensorimotor adaptive capacity. Indeed, enactivists appreciate parallels between their project and genetic epistemology:

By studying how children shape their worlds through sensorimotor actions, [Piaget] has done nothing less than study how the constitution of a perceptual object is grounded in ontogeny. Piaget successfully introduced the notion that cognition - even at what seems to be its highest level - is grounded in the concrete activity of the whole organism, that is, in sensorimotor coupling. In short: the world is not something that is given to us but something we engage in by moving, touching, breathing, and eating. This is what I call cognition as enaction since enaction connotes this bringing forth by concrete handling. (Varela, 1999, p. 8)

Grasp Actually
Yet, enactivists posit that their epistemology improves on Piaget's. Enactivist reading of Piaget queries his cognitive construct of a schema, as though it is an insufficientlyradical still-in-the-head ontology, whereas enactivist knowing is a systemic expression of the organism-environment intrinsically relational duality (for a similar dismissal of Piaget, see de Freitas \& Sinclair, 2014; for a rebuttal, see Abrahamson et al., 2016b, pp. 240-241; Turner, 1973). As such, enactivism would be more akin to ecological psychology, albeit the jury is still out on that alleged kinship (Di Paolo et al., 2021). Notwithstanding, in sifting through these theory innuendos, one can discern a confluence of genetic epistemology and enactivism:

In a nutshell, the enactive approach consists of two points: (1) perception consists in perceptually guided action and (2) cognitive structures emerge from the recurrent sensorimotor patterns that enable action to be perceptually guided. (Varela et al., 1991, pp. 172-173)

As such, enactivists would plausibly advocate for educational practice where students participate in perceptuomotor activities that occasion the emergence of conceptually critical cognitive structures (Hutto et al., 2015). Indeed, that enactivist philosophy could bear on transformative educational research is not lost upon its evangelists. In the words of enactivist epistemologist Petitmengin (2007):

[A]re our teaching methods well adapted? For at present, teaching consists in most cases of transmitting conceptual and discursive contents of knowledge. The intention is to fix a meaning, not to initiate a movement. Which teaching methods, instead of transmitting contents, could elicit the gestures which allow access to the source experience that gives these contents coherence and meaning? Such a teaching approach, based more on initiation than transmission, by enabling children and students to come into contact with the depth of their experience, could re-enchant the classroom. (p. 79, original italics)

This enactivist gauntlet to pedagogy was historically picked up by Pirie and Kieren $(1989,1992,1994)$, mathematics-education researchers who sought to implicate an alleged "primitive knowing," namely, sensorimotor dynamic-imagistic know-how, as structuring students' reasoning about formal concepts (for reviews, see Reid, 2014; Simmt \& Kieren, 2015). And while, perhaps, disagreeing on nuances of theory, enactivist math-ed researchers journey on a not-too-dissimilar path as their neo-Piagetian colleagues (Arnon et al., 2013; Kazunga \& Bansilal, 2020). They all seek to foster mathematics learning through concrete or virtual sensorimotor experiences (Sarama \& Clements, 2009). They all conceptualize cognitive structures coming forth from perception-for-action, namely, the ac- 
tion of manipulating the environment. Thinking is engaging the environment, whether that which we are handling is concrete, virtual, imaginary (MacIntyre et al., 2019), or some combination thereof (Hutto \& Sánchez-García, 2015; Kirsh, 2013; Liao \& Masters, 2001).

We have surveyed constructivist and enactivist theory of conceptual learning. These positions all agree that "cognitive structures emerge from the recurrent sensorimotor patterns that enable action to be perceptually guided" (Varela et al., 1991, p. 173). These cognitive structures are imputed to encompass "higher" forms of cognition, such as mathematical notions. We thus submit that comprehending mathematical objects is constituted in prehending perceptual structures. That is, individuals' experience of coming to grips with a mathematical idea is phenomenologically similar to that of gripping the environment in a way that promotes efficient interaction - in both cases, what is at stake is figuring out how to attend to the actual or imaginary percept so as to operate it in accord with one's objectives, as in the case of the diagonal line. As such, for any mathematical concept, the phenomenology of reasoning about it is grounded in a particular perception-for-action. Yet for this theoretical conviction to become a pedagogical reality, we further submit, educational designers must determine which specific perception-for-action could underlie the particular mathematical notion they are targeting; in turn, one must then determine which actions could give rise to that perception-for-action; next, one must create an activity that would elicit that action; and finally, one must devise a means for students to signify their emergent cognitive structures as mathematically meaningful (Abrahamson, 2014; Abrahamson et al., 2020, in press).

We now turn from the conceptual and theoretical sections of this paper to the empirical section, where we will demonstrate our thesis in the context of an embodieddesign research project that seeks to create for students of mathematical concepts "source experience that gives these contents coherence and meaning" (Petitmengin, 2007, p. 79). This project, we argue, solicits students' exapted capacity to form new perceptions-for-action that rise to the concrete as cognitive structures cultivated into mathematical ontologies.

\section{Evidence: Findings from Design-Based Research on the Mathematics Imagery Trainer}

Inspired by the embodied turn in the cognitive sciences, in particular by radical-constructivist and enactivist theories of epistemology, the Embodied Design Research
Laboratory at the University of California, Berkeley has been evaluating a theoretical view of mathematical reasoning as grounded in perceptuomotor activity (Abrahamson, 2019). Operating as a design-based research program, the objective has been to foster, document, and analyze students' multimodal phenomenology of developing perceptuomotor capacity to enact movement forms that instantiate mathematical concepts (Abrahamson \& Trninic, 2015). For example, raising both hands such that they move at different speeds instantiates proportional equivalence. Understanding a mathematical concept, as such, would be predicated on figuring out how to move in a new way - if you can't move it, you don't get it - and yet, to move in a new way, you must perceive the environment in a new way (Abrahamson \& Sánchez-García, 2016).

Perception is both necessary and sufficient for effecting motor action. Empirical research on perception, action, and cognition (Mechsner, 2003, 2004; Mechsner et al., 2001) has demonstrated the pivotal role of perception in organizing the enactment of complex motor action. This body of research rejects prior beliefs that the development of manual skills depends on improving motor coordination. As such, Mechsner's persuasive empirical research suggests that our theorization of physical-skill learning should shy away from modeling a would-be motor coordination as the learning objective, instead looking to the individual's apprehension of previously unattended perceptual gestalts as discovered ways of orienting to the environment.

\section{From Perception-for-Action to Mathematical Signification}

Our research program does not mitigate the role of symbolic registers in mathematical practice (Ernest, 2008). Rather, the program seeks to explain the microprocess of mathematics learning as two-stepped (Abrahamson, 2015): (a) developing a new perceptuomotor capacity (primitive knowing, Pirie \& Kieren, 1992, 1994; a pre-symbolic notion, Radford, 2013; know-how, Ryle, 1945; a concept image, Tall \& Vinner, 1981; immediate coping, Varela, 1999; a theorem-in-action, Vergnaud, 2009); and then (b) re-perceiving the movement form with respect to disciplinary frames of reference - that is, analyzing, modeling, and describing the form using quantitative measures and arithmetic routines to depict its constituent components, calculate relations between the components, determine invariant properties of the dy-
Abrahamson 
namic form, and extrapolate descriptors of the form's potential manifestations beyond the immediate context of the particular activity's situated constraints (Abrahamson et al., 2011). As such, the design program abides with the thesis that all knowing begins from movement (SheetsJohnstone, 2015), including mathematical knowing.

Along the designed process of enculturated epigenesis, a critical pedagogical phase is the mathematical signification of perceptual forms, similar to speaking of the diagonal line and viewing it as a hypothenuse. As will soon be exemplified, this process begins in our activities, when the teacher introduces supplementary resources into the students' working space (Abrahamson et al., 2012; Flood, 2018; Shvarts \& Abrahamson, 2019). In particular, the teacher may introduce symbolic artifacts - rudimentary mathematical tools, such as a grid, which, laid onto the working space, could potentiate a Cartesian coordinate plane onto an otherwise continuous space. Initially, students recognize in these new resources utilities for getting the job done according to the original activity task whether to facilitate their performance of a challenging bimanual coordination or to better enable them to monitor and discuss their strategy. But, in the course of appropriating these new resources into their perceptuomotor attentional routines, the students become dependent on these resources for enacting movements and reflecting on this enactment. The resources, which initially serve unreflective doing, thus emerge as frames of reference for reflective mathematical practice. Consequently, features of dynamic enactment become pinned down as specified static locations that can be named and measured. It is thus that moving in a new way becomes the grounding referent of a new mathematical concept.

\section{The Mathematics Imagery Trainer}

The empirical context for this research program to evaluate mathematical reasoning as perceptuomotor capacity is centered on a type of learning environment called the Mathematics Imagery Trainer (hence, "the Trainer"). The Trainer can be conceptualized as what Reed and Bril (1996), combining their respective perspectives from ecological psychology and intercultural developmental psychology, call a field of promoted action, that is, a socio-material space that occasions opportunities for novices to develop culturally valued dexterity through encountering and overcoming staged motor-control problems. As a field of promoted action, the Trainer constitutes an activity architecture where students learn to move in new ways through attempting to perform a motor-control task that requires developing new perceptions of the environment (Abrahamson \& Trninic, 2015): to move in a new way, you need to perceive in a new way (Mechsner et al., 2001).

Working with the Trainer, students face the task of manipulating selected features of the environment so as to effect a goal state, such as causing a screen to turn green. There are many ways to effect the Trainer's goal state, and students must figure out how to move while keeping the Trainer consistently in its goal state. By way of analogy, imagine you are participating in a most peculiar salsa lesson, where all the instructor does is let you know whenever your body is positioned appropriately you would need to "dot-to-dot" from one correct position to the next, until you figure out the overall choreography, at which point you will no longer need the teacher.

As Trainer students explore how to move smoothly "in green," they increasingly self-impose constraints on their degrees of freedom, so that their movement increasingly approximates the task's targeted form (Abrahamson \& Abdu, 2020). Reflecting on this new know-how, students articulate how one should move to perform the task. In so doing, students refer to the perceptual patterns they are attending to. These attentional anchors often combine actual and imaginary percepts into a gestalt. For example, in raising their hands such that the hands move at different speeds, students often report they are attending to the spatial interval between their hands - they increase this interval as they raise their hands. In response, the activity facilitator introduces mathematical instruments into the movement space, such as a grid. Students perceive in these instruments potentials for enhancing the enactment, evaluation, or explanation of their movement strategy. Yet in the course of utilizing the instruments' perceived affordances, the students shift into mathematical perceptions, where the instruments become frames of reference (Abrahamson et al., 2011). For example, students who have explained that they are simultaneously raising and increasing the interval between their hands will now shift into a motor-action plan using the grid lines as interim destinations: they raise their hands sequentially by different increments, with one hand rising in larger increments than the other, which results in an increasing interval between the rising hands (Fig. 3).

We have now come full circle back to the activity that gives rise to the spontaneous apprehension of a diagonal line that one imagines as a means of coordinating a complex bimanual movement. Eye-tracking studies (Duijzer et al., 2017) have corroborated data from our semi-struc- 


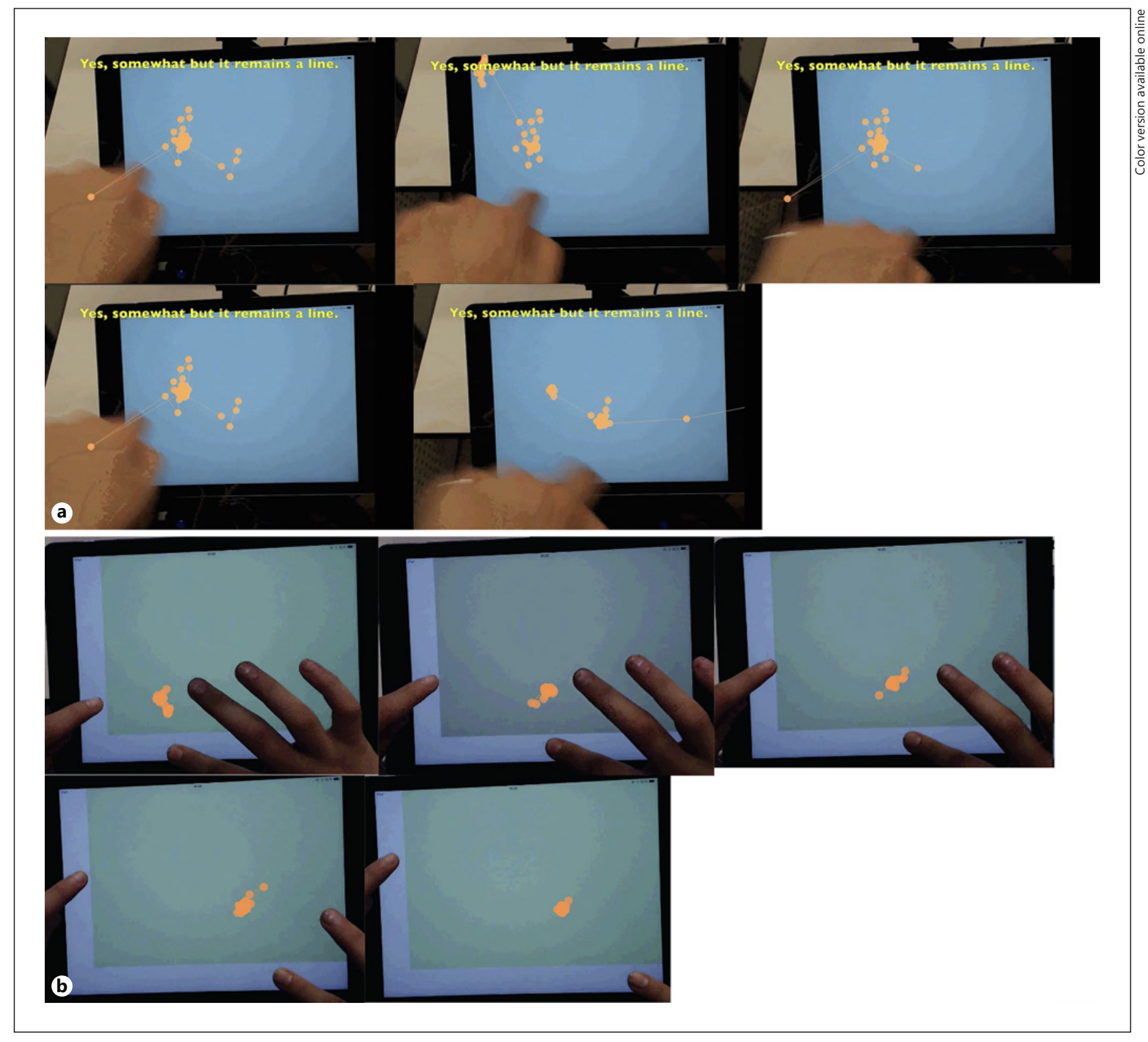

Fig. 3. a Lars, a 14-year-old low-tracked prevocational education Dutch student, gestures an imaginary diagonal line connecting his projected points of contact on the axes. b Lars uses an emergent attentional anchor to guide proportional bimanual coordination: he is keeping parallel the imaginary line between his fingertips.

tured clinical interviews (Abrahamson et al., 2011): to solve Trainer motor-control problems, students spontaneously generate new perception-for-action gestalts (Mechsner, 2003), the attentional anchors. Recall that an attentional anchor is a perceptual orientation toward the environment that enables the enactment of a goal movement by guiding the coordinated generation of constituent motor actions. Whether discovered or taught, atten- tional anchors constitute cognitive solutions to motorcontrol problems. Students refer to these constructed figments as bona fide objects they are manipulating. Figure 3 presents a sequence of screenshots featuring a typical behavior in Trainer activities. In this Mathematics Imagery Trainer for Proportion, the Orthogonals activity, which was engineered and trialed by Abrahamson's Dutch collaborators, students are to maintain their screen 
green by simultaneously moving their $\mathrm{LH}$ up/down and their $\mathrm{RH}$ right/left, that is, along orthogonal axes (Fig. 3; Abrahamson et al., 2016b). The screen is green when the hands' respective distances from the bottom-left origin point relate by the unknown ratio, here 1:2. Similar to numerous other students, Lars spontaneously discerned and described an imaginary diagonal line connecting his LH and $\mathrm{RH}$ index fingers (Fig. 3a). Lars maintains green by moving this imaginary diagonal line to the right, taking measures to keep it at a constant angularity to the base axis (Fig. 3b).

Across several Trainer evaluation studies for different mathematical domains, we are consistently gathering empirical data supporting the intriguing finding that attentional anchors emerge spontaneously as students' perceptual solution to the motor problem of coordinating the enactment of complex, often bimanual movement forms in our designed activities. The activity then occasions for students, like Lars, guided opportunities to reflect on how they are attending to the sensory manifold as they move their hands and to verbalize and draw these images. In sum, perception-for-action rises from the sensory manifold in the service of moving effectively in a field of promoted action, to become the cognitive structure of mathematical reasoning. As we have suggested, these nuanced sensations of immediate coping are initially ineffable yet, through appropriate guidance, can come forth as apprehensible experience that is accessible to conscious reflection and languaging (Morgan \& Abrahamson, 2016, 2018). As such, Trainer studies demonstrate the plausibility of theorizing our phenomenology of mathematical objects as action-oriented perceptions of the environment. Mathematical reasoning, thus, can be designed so as to draw on an action-oriented perceptuomotor mechanism that, I believe, is the very same mechanism that evolved for interacting with the natural environment. It is in this sense that mathematical practice exapts an ancient cognitive capacity.

\section{Conclusion}

[T] he roots of logical thought are not to be found in language alone, even though language coordinations are important, but are to be found more generally in the coordination of actions. (Piaget, 1968, p. 18)

Ontologically, mathematical objects are imaginary and intangible, yet, phenomenologically, mathematical objects are concrete for those who handle them (Wilensky, 1991). Mathematical reasoning, like any other form of reasoning, draws on cognitive capacity that originally evolved in the service of motor action (Melser, 2004). Mathematical reasoning draws on the same cerebral processes as motor action, so that, neurally, mathematical objects are treated as prehensible ontologies (McGilchrist, 2012). Like the black heron who exapted aerial kinesiology for aquatic predation, so, this paper has argued through theoretical consideration and empirical evidence, humanity exapted for mathematical practice its ancient ecologically adaptive capacity to formulate action-oriented sensory perceptions of the environment.

Still, this has been an argument about enculturated epigenesis, so how does culture figure in? When we study a mathematical concept, as in the case of the Mathematics Imagery Trainer, the concept is not objectively new. The concept has pre-existed us as a cultural legacy embedded in ongoing goal-oriented practice, just like the case of material artifacts, such as any mundane utensil we learn to use. And similar to operating material objects, in learning mathematics we need to learn how to move in a new way that achieves our task objective while satisfying the interaction constraints imposed by the cultural forms we engage. As such, humans endow legacy skills through engaging the young in guided activities using cultural artifacts, whether these are material or immaterial forms (Malafouris, 2013; Rogoff, 1990; Saxe, 2012; Tomasello, 2019). Thus, on the one hand, the literatures of ecological perception (Gibson, 1966, 1977; Turvey, 2019) and movement science (MacIntyre et al., 2019) assert that all organisms share the capacity to develop action-oriented perceptions of the environment, which is how we learn to move in new ways. Yet, on the other hand, human civilization's existential, material, and social circumstances, co-constituted with our species' evolving cognitive-linguistic capacities, have occasioned us opportunities to hone this perceptual phenomenology into non-arbitrary "things" that we language forth into our discourse, inscribe onto our environment, and thus distribute over artifacts, people, and time. We thus come to partake skillfully in cultural practice, including its action and discourse.

Mathematical objects are the stuff that mathematical practice is ultimately about - they are the symbolgrounding referents (cf. Harnad, 1990). Mathematical practice elaborates formally on these pre-symbolic notions (Radford, 2013): bringing them forth through action and gesture into language (Roth, 2014), framing and imbuing them with new meanings (Bartolini Bussi \& Mariotti, 2008), and converting and treating them through cascades of inter-signifying semiotic registers 
(Duval, 2006). This referential duality of mathematical concepts - as action and symbol, that is, as encompassing multimodal image schema in tandem with their formal definitions and semiotic presentations - has been discussed by mathematicians (Davis \& Hersh, 1981; Tao, 2016), ethnographers of mathematical practice (Hadamard, 1945), and educational researchers (Nemirovsky \& Ferrara, 2009; Presmeg, 1992; Schön, 1981; Sfard, 1991; Tall \& Vinner, 1981). Indeed, it has never been my intention to shrug the colossal semiotic cathedral of mathematical praxis. To wit, following Varela (1999), "My interest in immediate coping does not mean that I deny the importance of deliberation and analysis. My point is that it is important to understand the role and relevance of both cognitive modes" (p. 18). Focusing on immediate coping, this article has been concerned with perceptuomotor orientations to the environment that give rise and lend meaning to mathematical thinking. Thus, the biological form I have proposed as undergirding mathematical cognition bears phenomenological quality - it is a lived experience of perceiving and acting, an embodied cognitive form of enactment. As such, this proposal can be understood by way of the following juxtaposition with a competing theory.

Our phenomenology of mathematical ontologies as quasi-realistic entities is not due to some linguistic or pre-linguistic projection from an experiential source domain to some would-be abstract target domain, as delineated in the cognitive semantics theory of conceptual metaphor (cf. Lakoff \& Núñez, 2000). In fact, mathematical activity does not activate language areas of the brain at all (Amalric \& Dehaene, 2016). Rather, we literally experience mathematical ontologies as quasi-realistic entities, because human experience of imaginary entities evolved from the experience of real entities (Donald, 1991). To know is to grasp (cf. McGilchrist, 2012). As such, our use of spatial-temporal multimodal language in talking about mathematical objects is not because of the semiotic process of linguistic articulation (cf. Núñez et al., 1999) - it is about the fundamental phenomenological experience that would be articulated to begin with, that is, grasping, literally (Abrahamson, 2004, 2007). When metaphorical language is used to communicate a mathematical experience, this is not because mathematical concepts are metaphorical (cf. Gallagher \& Lindgren, 2015) - that would be a category error - but because metaphor is a means of fostering for others the enactive sensorimotor explorations that would lead them to developing concordant perceptions (Abrahamson, 2020; Abrahamson et al., 2016a; Tao, 2016). As such, having a sense of knowing is feeling that one has got a grasp on a situation (see Trninic, 2018, on Vygotsky's notion of kinesthetic sensations). To emphasize, it is not the case that we make mathematical ideas real through projecting metaphor. Rather, mathematical ideas seem real and possibly true to us when they are grounded in the experience of grasping, actually. Mathematical objects emerge from multimodal perceptuomotor solutions to situated problems of interacting adaptively with the ecology, whether natural, cultural, social, or combinations thereof (Abrahamson \& Trninic, 2015).

I have proposed that mathematical thinking is possible due to our biological capacity to develop an enactive grip on the world; that enactive grips on the world operate similarly in the case of imaginary objects, and that mathematical thinking, as such, is grounded in attentional anchors - dynamically invariant perceptual orientations that guide our action on the environment. This proposal differs from proposals from cognitive neuroscience that focus on innate and early developed spatiotemporal and enumerative capacities (Dehaene \& Brannon, 2011) or the implication of more advanced quantitativereasoningaselaborationson simpleapproximations (Jacob et al., 2012). These vying proposals - the phenomenological and the neuroscientific - I believe, should be in dialogue. For example, elsewhere I have discussed mathematics education as drawing on what I called perceptually privileged intensive quantities, that is, our apparently innate sensitivity to magnitudes of formal structure $a / b$, such as likelihood, slope, and density (Abrahamson, 2012; see also Thacker, 2019; Xu \& Garcia, 2008). But for this dialogue to be productive, I wager, we should not shy from epistemological issues surrounding the phenomenology of mathematics, because how we think mathematically must surely inform how we teach mathematics.

\section{Acknowledgment}

For their thoughts on an earlier draft, I wish to thank Geoff Saxe, Dragan Trninic, and Erin Pomponio. Comments from the Human Development Editor-in-Chief and Reviewers were immensely helpful.

\section{Statement of Ethics}

Figure 1 is from Wikipedia (creative commons, https://upload. wikimedia.org/wikipedia/commons/f/f5/Flickr_-_Rainbirder_-_ Black_Egret_\%28Egretta_ardesiaca\%29.jpg). For Figure 2, I include the following permission statement. "You have my permis-
90

Human Development 2021;65:77-93 DOI: $10.1159 / 000515680$
Abrahamson 
sion to use figures from my book, Cultural Development of Mathematical Ideas: Papua New Guinea Studies, in your manuscript 'Grasp Actually: Lessons from Evolutionary Biology for Mathematics Education.' You also have permission to make use of figures from my website, www.culturecognition.com, in the same manuscript" (Geoff Saxe, May 14, 2020, email communication). Figure 3 is from my own research. No ethics approval was required for this conceptual paper.

\section{Conflict of Interest Statement}

The author has no conflicts of interest to declare.

\section{Funding Sources}

No external funding sources were used in the writing of this paper.

\section{References}

Abrahamson, D. (2004). Embodied spatial articulation: A gesture perspective on student negotiation between kinesthetic schemas and epistemic forms in learning mathematics. In D. E. McDougall \& J. A. Ross (Eds.), Proceedings of the 26th Annual Meeting of the North American Chapter of the International Group for the Psychology of Mathematics Education (Vol. 2, pp. 791-797). Preney.

Abrahamson, D. (2007). Handling problems: Embodied reasoning in situated mathematics. In T. Lamberg \& L. Wiest (Eds.), Proceedings of the 29th Annual Meeting of the North American Chapter of the International Group for the Psychology of Mathematics Education (pp. 219-226). University of Nevada, Reno.

Abrahamson, D. (2009). Orchestrating semiotic leaps from tacit to cultural quantitative reasoning - The case of anticipating experimental outcomes of a quasi-binomial random generator. Cognition and Instruction, 27(3), 175-224. https://doi.org/10.1080/07370000903014261

Abrahamson, D. (2012). Rethinking intensive quantities via guided mediated abduction. Journal of the Learning Sciences, 21(4), 626649. https://doi.org/10.1080/10508406.2011. 633838

Abrahamson, D. (2014). Building educational activities for understanding: An elaboration on the embodied-design framework and its epistemic grounds. International Journal of ChildComputer Interaction, 2(1), 1-16. https://doi. org/10.1016/j.ijcci.2014.07.002

Abrahamson, D. (2015). The monster in the machine, or why educational technology needs embodied design. In V. R. Lee (Ed.), Learning technologies and the body: Integration and implementation (pp. 21-38). Routledge.

Abrahamson, D. (2019). A new world: Educational research on the sensorimotor roots of mathematical reasoning. In A. Shvarts (Ed.), Proceedings of the annual meeting of the Russian chapter of the International Group for the Psychology of Mathematics Education (PME) \& Yandex (pp. 48-68). Yandex.

Abrahamson, D. (2020). Strawberry feel forever: Understanding metaphor as sensorimotor dynamics. The Senses and Society, 15(2), 216238. https://doi.org/10.1080/17458927.2020. 1764742

Abrahamson, D., \& Abdu, R. (2020). Towards an ecological-dynamics design framework for embodied-interaction conceptual learning:
The case of dynamic mathematics environments. Educational Technology Research and Development. https://doi.org/10.1007/s11423020-09805-1

Abrahamson, D., \& Chase, K. (2020). Syntonicity and complexity: A design-based research reflection on the Piagetian roots of Constructionism. In N. Holbert, M. Berland, \& Y. Kafai (Eds.), Designing constructionist futures: The art, theory, and practice of learning designs (pp. 311-322). MIT Press.

Abrahamson, D., Dutton, E., \& Bakker, A. (in press). Towards an enactivist mathematics pedagogy. In S. A. Stolz (Ed.), The body, embodiment, and education: An interdisciplinary approach. Routledge.

Abrahamson, D., Gutiérrez, J. F., Charoenying, T., Negrete, A. G., \& Bumbacher, E. (2012). Fostering hooks and shifts: Tutorial tactics for guided mathematical discovery. Technology, Knowledge, and Learning, 17(1-2), 61-86. https://doi.org/10.1007/s10758-012-9192-7

Abrahamson, D., Nathan, M. J., Williams-Pierce, C., Walkington, C., Ottmar, E. R., Soto, H., \& Alibali, M. W. (2020). The future of embodied design for mathematics teaching and learning. Frontiers in Education, 5(147), 147. https://doi.org/10.3389/feduc.2020.00147

Abrahamson, D., \& Sánchez-García, R. (2016). Learning is moving in new ways: The ecological dynamics of mathematics education. Journal of the Learning Sciences, 25(2), 203239. https://doi.org/10.1080/10508406.2016. 1143370

Abrahamson, D., Sánchez-García, R., \& Smyth, C. (2016a). Metaphors are projected constraints on action: An ecological dynamics view on learning across the disciplines. In C.-K. Looi, J. L. Polman, U. Cress, \& P. Reimann (Eds.), "Transforming learning, empowering learners," Proceedings of the International Conference of the Learning Sciences (ICLS 2016) (Vol. 1, "Full Papers," pp. 314-321). International Society of the Learning Sciences.

Abrahamson, D., Shayan, S., Bakker, A., \& Van der Schaaf, M. F. (2016b). Eye-tracking Piaget: Capturing the emergence of attentional anchors in the coordination of proportional motor action. Human Development, 58(4-5), 218-244. https://doi.org/10.1159/000443153

Abrahamson, D., \& Trninic, D. (2015). Bringing forth mathematical concepts: Signifying sensorimotor enactment in fields of promoted action. ZDM Mathematics Education, 47(2), 295-306. https://doi.org/10.1007/s11858014-0620-0

Abrahamson, D., Trninic, D., Gutiérrez, J. F., Huth, J., \& Lee, R. G. (2011). Hooks and shifts: A dialectical study of mediated discovery. Technology, Knowledge, and Learning, 16(1), 55-85. https://doi.org/10.1007/s10758-0119177-y

Alberto, R. A., Bakker, A., Walker-van Aalst, O., Boon, P. B. J., \& Drijvers, P. H. M. (2019). Networking theories in design research: An embodied instrumentation case study in trigonometry. In U. T. Jankvist, v. d. Heuvel-Panhuizen, \& M. Veldhuis (Eds.), Proceeding of the 11th Congress of the European Society for Research in Mathematics Education (CERME11) (pp. 3088-3095). Freudenthal Group \& Freudenthal Institute, Utrecht University and ERME.

Amalric, M., \& Dehaene, S. (2016). Origins of the brain networks for advanced mathematics in expert mathematicians. Proceedings of the National Academy of Sciences of the United States of America, 113(18), 4909-4917. https://doi.org/10.1073/pnas.1603205113

Araújo, D., Davids, K., \& Renshaw, I. (2020). Cognition, emotion, and action in sport: And ecological dynamics approach. In G. Tenenbaum \& R. C. Eklund (Eds.), Handbook of sport psychology (4th ed., pp. 535-555). John Wiley \& Sons. https://doi.org/10.1002/ 9781119568124.ch25

Arnon, I., Cottrill, J., Dubinsky, E., Oktaç, A., Roa Fuentes, S., Trigueros, M., \& Weller, K. (2013). APOS theory: A framework for research and curriculum development in mathematics education. Springer Science \& Business Media.

Bartolini Bussi, M. G., \& Mariotti, M. A. (2008). Semiotic mediation in the mathematics classroom: Artefacts and signs after a Vygotskian perspective. In L. D. English, M. G. Bartolini Bussi, G. A. Jones, R. Lesh, \& D. Tirosh (Eds.), Handbook of international research in mathematics education (2nd ed., pp. 720-749). Lawrence Erlbaum Associates.

Boer, T. (1978). The development of Husserl's thought. Springer. https://doi.org/10.1007/97894-009-9691-5

Bongers, T., Alberto, T., \& Bakker, A. (2018). Results from MITp-Orthogonal post-test [Unpublished raw data]. Utrecht University. 
Casasanto, D. (2010). Space for thinking. In V. Evans \& P. Chilton (Eds.), Language, cognition and space: The state of the art and new directions (pp. 453-478). Equinox.

Cobb, P., Confrey, J., diSessa, A., Lehrer, R., \& Schauble, L. (2003). Design experiments in educational research. Educational Researcher, 32(1), 9-13. https://doi.org/10.3102/ 0013189X032001009

Cole, M., \& Wertsch, J. V. (1996). Beyond the individual-social antinomy in discussions of Piaget and Vygotsky. Human Development, 39(5), 250-256. https://doi.org/10.1159/000278475

Damşa, C., \& Jornet, A. (2020). The unit of analysis in learning research: Approaches for imagining a transformative agenda. Learning, Culture and Social Interaction. https://doi. org/10.1016/j.lcsi.2020.100407

Darwin, C. (1859). On the origin of species by means of natural selection, or Preservation of favoured races in the struggle for life. John Murray.

Davis, P. J., \& Hersh, R. (1981). The mathematical experience. Birkhäuser.

de Freitas, E., \& Sinclair, N. (2014). Mathematics and the body: Material entanglements in the classroom. Cambridge University Press. https://doi.org/10.1017/CBO9781139600378

Dehaene, S., \& Brannon, E. (Eds.) (2011). Space, time and number in the brain: Searching for the foundations of mathematical thought. Elsevier Academic Press.

Di Paolo, E. A., Chemero, A., Heras-Escribano, M., \& McGann, M. (Eds.) (2021). Enaction and ecological psychology: Convergences and complementarities. Frontiers in Psychology.

diSessa, A. A., Levin, M., \& Brown, N. J. S. (Eds.) (2015). Knowledge and interaction: A synthetic agenda for the learning sciences. Routledge.https://doi.org/10.4324/9781315757360

Donald, M. (1991). Origins of the modern mind: Three stages in the evolution of culture and cognition. Harvard Press.

Dreyfus, H. L., \& Dreyfus, S. E. (1999). The challenge of Merleau-Ponty's phenomenology of embodiment for cognitive science. In G. Weiss \& H. F. Haber (Eds.), Perspectives on embodiment: The intersections of nature and culture (pp. 103-120). Routledge.

Duijzer, A. C. G., Shayan, S., Bakker, A., van der Schaaf, M. F., \& Abrahamson, D. (2017). Touchscreen tablets: Coordinating action and perception for mathematical cognition. Frontiers in Psychology, 8, 144. https://doi. org/10.3389/fpsyg.2017.00144

Duval, R. (2006). A cognitive analysis of problems of comprehension in a learning of mathematics. Educational Studies in Mathematics, 61(1-2), 103-131. https://doi.org/10.1007/ s10649-006-0400-z

Ernest, P. (2008). Towards a semiotics of mathematics text (part 1). For the Learning of Mathematics, 28(1), 2-8.

Flood, V. J. (2018). Multimodal revoicing as an interactional mechanism for connecting scientific and everyday concepts. Human Development, 61(3), 145-173. https://doi.org/ $10.1159 / 000488693$
Gallagher, S., \& Lindgren, R. (2015). Enactive metaphors: Learning through full-body engagement. Educational Psychology Review, 27(3), 391-404. https://doi.org/10.1007/ s10648-015-9327-1

Gibson, J. J. (1966). The senses considered as perceptual systems. Houghton Mifflin.

Gibson, J. J. (1977). The theory of affordances. In R. Shaw \& J. Bransford (Eds.), Perceiving, acting and knowing: Toward an ecological psychology (pp. 67-82). Lawrence Erlbaum Associates.

Glenberg, A. M. (2006). Radical changes in cognitive process due to technology: A jaundiced view. Pragmatics \& Cognition, 14(2), 263274. https://doi.org/10.1075/pc.14.2.07gle

Gould, S. J., \& Vrba, E. S. (1982). Exaptation - A missing term in the science of form. Paleobiology, 8(1), 4-15. https://doi.org/10.1017/ S0094837300004310

Hadamard, J. (1945). The psychology of invention in the mathematical field. Dover.

Harnad, S. (1990). The symbol grounding problem. Physica D. Nonlinear Phenomena, 42(13), 335-346. https://doi.org/10.1016/01672789(90)90087-6

Heidegger, M. (1962). Being and time (J. Macquarrie \& E. Robinson, Trans.). Harper \& Row. (Original work published 1927)

Hutto, D. D., \& Myin, E. (2013). Radicalizing enactivism: Basic minds without content. MIT Press. https://doi.org/10.7551/mitpress/ 9780262018548.001.0001

Hutto, D. D., \& Myin, E. (2017). Evolving enactivism: Basic minds meet content. MIT Press. h t tps://doi.org/10.7551/ mit press/9780262036115.001.0001

Hutto, D. D., Kirchhoff, M. D., \& Abrahamson, D. (2015). The enactive roots of STEM: Rethinking educational design in mathematics. Educational Psychology Review, 27(3), 371389. https://doi.org/10.1007/s10648-0159326-2

Hutto, D. D., \& Sánchez-García, R. (2015). Choking RECtified: Embodied expertise beyond Dreyfus. Phenomenology and the Cognitive Sciences, 14(2), 309-331. https://doi. org/10.1007/s11097-014-9380-0

Jacob, S. N., Vallentin, D., \& Nieder, A. (2012). Relating magnitudes: The brain's code for proportions. Trends in Cognitive Sciences, 16(3), 157-166. https://doi.org/10.1016/j. tics.2012.02.002

Jelec, A. (2014). Are abstract concepts like dinosaur feathers? Conceptual Metaphor Theory and conceptualisation strategies in gesture of blind and visually impaired children. Poznań.

Kazunga, C., \& Bansilal, S. (2020). An APOS analysis of solving systems of equations using the inverse matrix method. Educational Studies in Mathematics, 103(3), 339-358. https://doi. org/10.1007/s10649-020-09935-6

Kirsh, D. (2013). Embodied cognition and the magical future of interaction design. ACM Transactions on Human-Computer Interaction, 20(1), 3:1-30. https://doi.org/10.1145/ 2442106.2442109
Koschmann, T., Kuuti, K., \& Hickman, L. (1998). The concept of breakdown in Heidegger, Leont'ev, and Dewey and its implications for education. Mind, Culture, and Activity, 5(1), 25-41. https://doi.org/ 10.1207/s15327884mca0501_3

Lakoff, G., \& Núñez, R. E. (2000). Where mathematics comes from: How the embodied mind brings mathematics into being. Basic Books.

Landy, D., \& Goldstone, R. L. (2007). How abstract is symbolic thought? Journal of Experimental Psychology. Learning, Memory, and Cognition, 33(4), 720-733. https://doi. org/10.1037/0278-7393.33.4.720

Liao, C. M., \& Masters, R. S. (2001). Analogy learning: A means to implicit motor learning. Journal of Sports Sciences, 19(5), 307-319. https://doi.org/10.1080/02640410152006081

MacIntyre, T. E., Madan, C. R., Brick, N. E., Beckmann, J., \& Moran, A. P. (2019). Imagery, expertise, and action: A window into embodiment. In M. L. Cappuccio (Ed.), Handbook of embodied cognition and sport psychology (pp. 625-650). MIT Press.

Malafouris, L. (2013). How things shape the mind. MIT Press. https://doi.org/10.7551/mitpress/9476.001.0001

Maturana, H. R., \& Varela, F. J. (1992). The tree of knowledge: The biological roots of human understanding. Shambala Publications. (Original work published 1987.)

McGilchrist, I. (2012). The master and his emissary: The divided brain and the making of the western world. Yale University Press.

Mechsner, F. (2003). Gestalt factors in human movement coordination. Gestalt Theory, 25(4), 225-245

Mechsner, F. (2004). A psychological approach to human voluntary movement. Journal of $\mathrm{Mo}$ tor Behavior, 36(4), 355-370. https://doi.org/ 10.1080/00222895.2004.11007993

Mechsner, F., Kerzel, D., Knoblich, G., \& Prinz, W. (2001). Perceptual basis of bimanual coordination. Nature, 414(6859), 69-73. https:// doi.org/10.1038/35102060

Melser, D. (2004). The act of thinking. MIT Press. https://doi.org/10.7551/mitpress/ 1078.001.0001

Merleau-Ponty, M. (1964). The primacy of perception, and other essays on phenomenological psychology, the philosophy of art, history and politics (C. Smith, Trans.). Northwestern University Press.

Morgan, P., \& Abrahamson, D. (2016). Cultivating the ineffable: The role of contemplative practice in enactivist learning. For the Learning of Mathematics, 36(3), 31-37.

Morgan, P., \& Abrahamson, D. (2018). Applying contemplative practices to the educational design of mathematics content: Report from a pioneering workshop. The Journal of Contemplative Inquiry, 5(1), 107-119.

Nagataki, S., \& Hirose, S. (2007). Phenomenology and the third generation of cognitive science: Towards a cognitive phenomenology of the body. Human Studies, 30(3), 219-232. https:// doi.org/10.1007/s10746-007-9060-y 
Nathan, M. J., \& Walkington, C. (2017). Grounded and embodied mathematical cognition: Promoting mathematical insight and proof using action and language. Cognitive Research: Principles and Implications, 2(1), 9. https://doi.org/10.1186/s41235-016-0040-5

Nemirovsky, R., \& Ferrara, F. (2009). Mathematical imagination and embodied cognition. Educational Studies in Mathematics, 70(2), 159-174. https://doi.org/10.1007/s10649008-9150-4

Newell, K. M., \& Ranganathan, R. (2010). Instructions as constraints in motor skill acquisition. In I. Renshaw, K. Davids, \& G. J. P. Savelsbergh (Eds.), Motor learning in practice: A constraints-led approach (pp. 17-32). Routledge.

Núñez, R. E., Edwards, L. D., \& Matos, J. F. (1999). Embodied cognition as grounding for situatedness and context in mathematics education. Educational Studies in Mathematics, 39(1), 45-65. https://doi.org/10.1023/A: 1003759711966

Ottmar, E., \& Landy, D. (2017). Concreteness fading of algebraic instruction: Effects on learning. Journal of the Learning Sciences, 26(1), 51-78. https://doi.org/10.1080/10508406.201 6.1250212

Petitmengin, C. (2007). Towards the source of thoughts: The gestural and transmodal dimension of lived experience. Journal of Consciousness Studies, 14(3), 54-82.

Piaget, J. (1968). Genetic epistemology (E. Duckworth, Trans.). Columbia University Press.

Pirie, S. E. B., \& Kieren, T. E. (1989). A recursive theory of mathematical understanding. For the Learning of Mathematics, 9(3), 7-11.

Pirie, S. E. B., \& Kieren, T. E. (1992). Creating constructivist environments and constructing creative mathematics. Educational Studies in Mathematics, 23(5), 505-528. https://doi. org/10.1007/BF00571470

Pirie, S. E. B., \& Kieren, T. E. (1994). Growth in mathematical understanding: How can we characterize it and how can we represent it? Educational Studies in Mathematics, 26(2-3), 165-190.https://doi.org/10.1007/BF01273662

Presmeg, N. C. (1992). Prototypes, metaphors, metonymies and imaginative rationality in high school mathematics. Educational Studies in Mathematics, 23(6), 595-610. https://doi. org/10.1007/BF00540062

Radford, L. (2013). Sensuous cognition. In D. Martinovic, V. Freiman, \& Z. Karadag (Eds.), Visual mathematics and cyberlearning (Mathematics education in digital era) (Vol. 1, pp. 141-162). Springer. https://doi. org/10.1007/978-94-007-2321-4_6

Reed, E. S., \& Bril, B. (1996). The primacy of action in development. In M. L. Latash \& M. T. Turvey (Eds.), Dexterity and its development (pp. 431-451). Lawrence Erlbaum Associates.
Reid, D. A. (2014). The coherence of enactivism and mathematics education research: A case study. Avant, V(2), 137-172. https://doi. org/10.26913/50202014.0109.0007

Rogoff, B. (1990). Apprenticeship in thinking: Cognitive development in social context. Oxford University Press.

Roth, W.-M. (2014). On the pregnance of bodily movement and geometrical objects: A postconstructivist account of the origin of mathematical knowledge. Journal of Pedagogy, 5(1), 65-89. https://doi.org/10.2478/jped2014-0004

Ryle, G. (1945). Knowing how and knowing that: The presidential address. Proceedings of the Aristotelian Society, 46(1), 1-16. https://doi. org/10.1093/aristotelian/46.1.1

Sarama, J., \& Clements, D. H. (2009). "Concrete" computer manipulatives in mathematics education. Child Development Perspectives, 3(3), 145-150. https://doi.org/10.1111/j.17508606.2009.00095.x

Saxe, G. B. (2012). Cultural development of mathematical ideas: Papua New Guinea studies. Cambridge University Press. https://doi. org/10.1017/CBO9781139045360

Schön, D. A. (1981). Intuitive thinking? A metaphor underlying some ideas of educational reform (Working Paper 8). Division for Study and Research in Education, M.I.T.

Sfard, A. (1991). On the dual nature of mathematical conceptions: Reflections on processes and objects as different sides of the same coin. Educational Studies in Mathematics, 22(1), 1-36. https://doi.org/10.1007/BF00302715

Sheets-Johnstone, M. (2015). Embodiment on trial: A phenomenological investigation. Continental Philosophy Review, 48(1), 23-39. https://doi.org/10.1007/s11007-014-9315-z

Shvarts, A. (2017). Eye movements in emerging conceptual understanding of rectangle area. In B. Kaur, W. K. Ho, T. L. Toh, \& B. H. Choy (Eds.), Proceedings of the 41st Conference of the International Group for the Psychology of Mathematics Education (Vol. 1, p. 268). PME.

Shvarts, A., \& Abrahamson, D. (2019). Dual-eyetracking Vygotsky: A microgenetic account of a teaching/learning collaboration in an embodied-interaction technological tutorial for mathematics. Learning, Culture and Social Interaction, 22, 100316. https://doi. org/10.1016/j.lcsi.2019.05.003

Simmt, E., \& Kieren, T. (2015). Three "moves" in enactivist research: A reflection. ZDM Mathematics Education, 47(2), 307-317. https:// doi.org/10.1007/s11858-015-0680-9

Smith, L. B., Thelen, E., Titzer, R., \& McLin, D. (1999). Knowing in the context of acting: The task dynamics of the A-not-B error. Psychological Review, 106(2), 235-260. https://doi. org/10.1037/0033-295X.106.2.235

Steffe, L. P., \& Kieren, T. (1994). Radical constructivism and mathematics education. Journal for Research in Mathematics Education, 25(6), 711-733. https://doi.org/10.2307/749582
Stetsenko, A. (2017). The transformative mind: Expanding Vygotsky's approach to development and education. Cambridge University Press.https://doi.org/10.1017/9780511843044

Tall, D., \& Vinner, S. (1981). Concept image and concept definition in mathematics with particular reference to limits and continuity. $E d-$ ucational Studies in Mathematics, 12(2), 151169. https://doi.org/10.1007/BF00305619

Tao, T. (2016). Thinking and explaining. mathOverflow. https://mathoverflow.net/ questions/38639/thinking-and-explaining.

Thacker, I. (2019). An embodied design for grounding the mathematics of slope in middle school students' perceptions of steepness. Research in Mathematics Education, 22(3), 304-28. https://doi.org/10.1080/14794802.20 19.1692061

Tomasello, M. (2019). Becoming human: A theory of ontogeny. Harvard University Press. https:// doi.org/10.4159/9780674988651

Trninic, D. (2018). Instruction, repetition, discovery: Restoring the historical educational role of practice. Instructional Science, 46(1), 133-153. https://doi.org/10.1007/s11251017-9443-z

Turner, T. (1973). Piaget's structuralism (review article). American Anthropologist, 75(2), 351373. https://doi.org/10.1525/aa.1973.75.2. 02a00010

Turvey, M. T. (2019). Chapter 22: Ontology at the ecological scale. In: Lectures on perception: An ecological perspective. Routledge/Taylor \& Francis.

Varela, F. J. (1999). Ethical know-how: Action, wisdom, and cognition. Stanford University Press.

Varela, F. J., Thompson, E., \& Rosch, E. (1991). The embodied mind: Cognitive science and human experience. MIT Press. https://doi. org/10.7551/mitpress/6730.001.0001

Vergnaud, G. (2009). The theory of conceptual fields. Human Development, 52, 83-94. https://doi.org/10.1159/000202727

von Glasersfeld, E. (1987). Learning as a constructive activity. In C. Janvier (Ed.), Problems of representation in the teaching and learning of mathematics (pp. 3-18). Lawrence Erlbaum.

Wilensky, U. (1991). Abstract meditations on the concrete and concrete implications for mathematics education. In I. Harel \& S. Papert (Eds.), Constructionism (pp. 193-204). Ablex Publishing Corporation.

Wilson, A. D., \& Golonka, S. (2013). Embodied cognition is not what you think it is. Frontiers in Psychology, 4, 58. https://doi.org/10.3389/ fpsyg.2013.00058

Xu, F., \& Garcia, V. (2008). Intuitive statistics by 8 -month-old infants. Proceedings of the $\mathrm{Na}$ tional Academy of Sciences of the United States of America, 105(13), 5012-5015. https://doi.org/10.1073/pnas.0704450105 